\title{
Ser o no ser católico en América Latina: el dilema vigente
}

Marco Antonio Quesada Chaves Escuela Ecuménica de Ciencias de la Religión

Instituto de Estudios Latinoamericanos

Universidad Nacional, Costa Rica

\section{Resumen}

La situación de lo religioso en América Latina mostrada por dos importantes estudios como lo son el del Pew Research Center y el Latinobarómetro, ambos realizados en 2014, denotan una serie de transformaciones importantes en la manera como es entendido, asumido y vivido lo religioso por la mayoría de latinoamericanos(as). Se atiende a un decrecimiento en el número de personas que se identifican como católicas, a su vez que hay un creciente número de protestantes y un tercer grupo que no posee filiación religiosa alguna, pero que no deja de ser religioso. A partir de una perspectiva histórico-teológica, el presente artículo discute dos fenómenos que se encuentran en la presente situación: el de la secularización desde la realidad latinoamericana y el de los llamados "católicos culturales”, un fenómeno complejo, paradójico como también desafiante.

Palabras claves: religión, América Latina, secularización, Catolicismo, cultura

\begin{abstract}
The situation of the religious subject in Latin America shown by two important studies such as the Pew Research Center and the Latinobarómetro; both carried out in 2014, denote a series of important transformations in the way this subject is understood, assumed and lived by the majority of Latin Americans. There is a decrease in the number of people who identify themselves as Catholics, in turn there is a growing number of Protestants, and a third group that does not have any religious affiliation, but which is still religious. From a historical-theological perspective, the present article discusses two phenomena that are found in the present situation: that of secularization from the Latin American reality, and that of the so-called "cultural Catholics"; a complex phenomenon, paradoxical as well as challenging.
\end{abstract}

Keywords: religion, Latin America, secularization, Catholicism, culture 


\section{Introducción. El contexto que nos convoca}

"Hemos pasado de una sociedad marcada por la cristiandad a otra abierta y diversificada. Es una situación completamente nueva en la historia de la humanidad." Charles Taylor (1931-)

A punto de entrar en la segunda década del siglo XXI, América Latina se encuentra en una situación particularmente interesante en lo que se refiere a lo religioso y lo espiritual; en definitiva, al sentido último de la vida. De ser una región histórica y predominantemente católica, se han venido atendiendo, en las últimas décadas del siglo XX e inicios del actual, unos cambios progresivos en la composición religiosa de la población, pero sobre todo, a transformaciones más profundas que tienen que ver con la forma en que las personas entienden, redefinen y viven lo religioso, lo espiritual. Se constata una disminución en el número de personas que se identifican como católicos(as), siendo así que según los sondeos realizados por el Latinobarómetro entre 1995 y 2013, hay una disminución de 0.7 puntos porcentuales al año en el número de personas que se vinculan a la Iglesia Católica, pero curiosamente muchas no dejan de ser religiosas, o dejan de lado la dimensión espiritual en sus vidas, sino que se unen a iglesias protestantes: "Lejos de abandonar las religiones los latinoamericanos lo que hacen es abrazar otra religión cuando abandonan el catolicismo. Es lo que vemos al observar la evolución de las religiones por país." (Latinobarómetro, 2014, p. 4)

Durante la mayor parte del siglo XX hasta entrada la década de los años 60, alrededor de un $90 \%$ de la población latinoamericana se definía como católica; en la actualidad y según el último estudio realizado por el Pew Research Center (2014), un 69\% de la población se identifica con el Catolicismo, similar al 67\% que arrojó el Latinobarómetro (Latinobarómetro, 2014). A grandes rasgos, los motivos esgrimidos para dicho cambio son sobre todo dos:

a. Un creciente sector de la población se ha venido uniendo a diversas iglesias protestantes, principalmente evangélicas y neo-pentecostales cuyo crecimiento en la región es constante desde la década de los 70. Actualmente, $19 \%$ se identifican como protestantes (Pew Research Center, 2014).

b. Un rechazo e indiferencia cada vez mayor hacia la religión institucional, organizada, pues un $8 \%$ no se afilia a ninguna religión en particular (Pew Research Center, 2014).

Tenemos, así, un fenómeno que se bifurca en dos direcciones distintas: quienes por una parte desean seguir vinculados al Cristianismo, pero en otras iglesias cristianas, cambiando así su filiación eclesial, mientras que en la otra dirección se tiene a un creciente sector de la población que si bien no se identifican con una religión en específico, no necesariamente se identifican como ateos o agnósticos: "En toda América Latina, así como entre los hispanos en Estados Unidos, la mayoría de las personas que no tienen afiliación dicen que no tienen una religión en particular, en lugar de describirse como ateos o agnósticos." (Pew Research Center, 2014, p. 15).

En este sentido, se puede encontrar una gran pluralidad de formas de vivir la 
espiritualidad o lo religioso; pluralidad que, vale decirlo, es muy difícil de precisar por su misma ambigüedad. Por mencionar sólo algunos ejemplos: están quienes no necesariamente rechazan del todo el Cristianismo, pero tampoco quieren vincularse a una comunidad de fe, sino más bien vivir la espiritualidad cristiana a su manera, y según sus disposiciones. Otros se unen a otras religiones que en las últimas décadas se están instalando en el continente, tales como la New Age, la cual en sí no es una religión, sino una constelación de espiritualidades donde se sincretizan elementos de varias tradiciones religiosas, algo así como una sopa de religiones; el Budismo, el cual al ser una religión no-teísta ha tenido una interesante influencia en ambientes intelectuales, académicos, científicos y en movimientos pacifistas (Tizzano, 2012); el Taoísmo, cuya influencia estriba sobre todo en la promoción cultural por parte de varias instituciones chinas, lo cual incluye la práctica de la Medicina Tradicional China, y de disciplinas psicofísicas y espirituales como el Tai Chi o el Chi Kung, muy populares entre algunos sectores; el Hinduismo, cuya mayor presencia se da a partir de la práctica del Yoga en numerosas escuelas y mediante la comercialización masiva de productos y videos para el autoaprendizaje.

Existen otras religiones tales como el Judaísmo y el Islam, pero representan un porcentaje pequeño en la región y están más vinculadas a las poblaciones migrantes provenientes de Medio Oriente. La Santería, y cultos denominados Neoindios, también aparecen en el espectro religioso, pero su incidencia también es porcentualmente muy reducida para considerarse significativa. Es de notar, sin embargo, que en la relación de las personas con todas estas religiones varía el nivel de aceptación de las doctrinas y el involucramiento en las prácticas, donde hay unos procesos de aculturación e inculturación muy variables que se deben tomar en cuenta, sobre todo en cuanto a las religiones provenientes de Asia.

Finalmente, hay otros que siguiendo una definición que se ha popularizado, no se consideran religiosos pero sí espirituales según su propia definición. Otros simplemente no se consideran creyentes, donde predominan diversas formas de ateísmo o agnosticismo, entre muchas manifestaciones. Sin embargo, en los niveles estadísticos, se aprecia cómo la región prácticamente se reparte entre católicos, protestantes (de diversas denominaciones) $\mathrm{y}$ quienes no se identifican con ninguna religión en particular, presentándose así la variedad que se acaba de comentar.

Es considerable lo que podría analizarse y discutirse sobre ambas tendencias, pero el interés y reflexiones del presente artículo versan en torno al segundo grupo. Es sugestivo notar que estas formas más individualizadas y personalizadas de vivir lo religioso-espiritual implican, en muchas ocasiones, adoptar ideas, prácticas y elementos simbólicos de otras religiones. A su vez, existe una "occidentalización" de algunas de estas tradiciones religiosas tales como el Budismo zen, el Yoga o el Tai Chi que es importante considerar. Es decir, la adaptación, modificación y reimaginación según los cánones de la mentalidad cultural occidental. Ello es en buena parte consecuencia del progresivo intercambio religioso y cultural entre América Latina y el resto del mundo, por una acelerada 
globalización de la que, justamente, se comenzó a hablar de manera más concreta en la década de los 60 (Steger, 2009) década en la cual se empieza a observar esta tendencia a distanciarse de la Iglesia Católica, y en la que también ésta realizó el Concilio Vaticano II, como una respuesta ante los desafíos del mundo actual en constante evolución.

La globalización contemporánea -tal y como la conocemos- es un complejo proceso multidimensional: histórico, geopolítico, económico y cultural que se viene gestando desde finales del siglo XV y en el transcurso del XVI con dos grandes acontecimientos: el mal llamado "descubrimiento" de América y la Reforma Protestante acaecida en Europa (Steger, 2009; Ferrer, 2013) acontecimiento este último de cuyas consecuencias América Latina ha ido participando a un ritmo propio, según su contexto histórico, geopolítico y cultural, que vale recordarlo, es muy distinto al norteamericano y europeo. A diferencia de Norteamérica, sobre todo Estados Unidos, en cuya naciente sociedad estuvo muy presente el Protestantismo, la conquista y colonización emprendidas por el Imperio español de lo que sería América Latina, trajo consigo el Catolicismo como la denominación cristiana predominante. Por ende, la expansión de las nacientes ideas liberales del individualismo y una menor intervención de los gobiernos en la vida social -fruto de las ideas protestantes- no llegaron a calar en la región sino hasta entrados los siglos XVIII y XIX.

Puede apreciarse, entonces, que el panorama religioso mostrado por ambos estudios aparte de enrevesado, incierto, como ambiguo y plural en sus manifestaciones, tiene también unos antecedentes históricos que pueden ser identificados, analizados y discutidos, por ello sigue abierta la cuestión acerca de su significado así como sobre su ulterior desarrollo. Aquí no hay espacio para determinismos ingenuos $o$ respuestas definitivas, sino propuestas de reflexión; tratamos con un fenómeno vivo, en constante evolución, como lo es la experiencia religiosa.

Al tener en mente la presente situación, es necesario esbozar algunas reflexiones histórico-teológicas sobre dos aspectos que destacan. El primero, sobre cómo se está dando el proceso de secularización en la región, el cual viene aparejado a estas transformaciones en lo religioso y en lo espiritual, ya que es a partir de la década de los 60 cuando se empiezan a observar dichas transformaciones en la región; también, cómo era predominante un discurso en las Ciencias Sociales sobre la secularización del mundo occidental -incluida América Latina-, en el cual ésta parecía ser un "proceso ineluctable” (Blancarte, 2012, p. 60). Ahora, como se empieza a reconocer, las sociedades occidentales no sólo no se han secularizado del todo, sino que la religión se fortalece y se transforma de una manera impredecible (Blancarte, 2012). Viejas pseudopredicciones heredadas del rancio positivismo cientificista que imperó durante el siglo XIX entre algunas élites intelectuales, y que ingenuamente vaticinaba la desaparición de la religión, vuelven a darse de bruces contra una dimensión fundamental del ser humano que se resiste a sucumbir.

El segundo aspecto, por otra parte, nos remite a una situación que resalta de manera 
sutil, poco verbalizada, y que cabe indagar teológicamente. Si bien los datos arrojados por los estudios mencionados son por sí mismos reveladores, no abordan una cuestión importante: el dilema de ser "católicos culturales". Es decir, quienes aún sin profesar el Cristianismo -sobre todo católico- han crecido y se desenvuelven en una región latinoamericana que ha sido y es culturalmente cristiana, donde la Iglesia Católica es junto a las instituciones políticas heredadas de la Colonia, una de las que cimentó las bases de las actuales sociedades ya que desde el siglo XVI hasta el XVIII, la formación de la cultura latinoamericana se da a partir de un importante sustrato católico (Legorreta, 2013).

¿Cómo entender entonces la subjetividad de alguien quien, por ejemplo, sin considerarse cristiano(a), ha crecido en una cultura cuya cosmovisión y significados se han forjado en el seno del Cristianismo? ¿Cómo conjugar ambas realidades en apariencia disímiles? Si partimos de la premisa de la Psicología Cultural de que mente y cultura se constituyen mutuamente, de que la subjetividad humana se desarrolla en íntima relación con el entorno sociocultural (Bruner, 2015; Guitart, 2009), ello resulta aún más esclarecedor, como complejo y problemático. El estudio del Pew Resarch (2014) afirma, por ejemplo, que hasta un $84 \%$ de los latinoamericanos fueron bautizados $\mathrm{y}$ criados(as) como católicos, independientemente de la orientación religiosa o noreligiosa que luego le dieran a su vida. Esta situación de ser culturalmente católicos es asumida de formas muy variadas, desde ser una especie de limbo, transición psicosocial, religiosa y moral para algunos, como fuente de contradicciones y conflictos existenciales muy virulentos para otros, $\mathrm{o}$ bien, una fuente de identidad cultural, religiosa para otros. Es un dilema que posee también fuertes implicaciones teológicas hacia lo interno del Catolicismo, las cuales se comentarán; pero es un fenómeno del que no sabemos para dónde va, o en qué va a resultar en las próximas décadas.

\section{¿Secularización en proceso? Lo diferente del contexto latinoamericano}

“En América Latina, lo maravilloso se encuentra a la vuelta de cada esquina, en el desorden, en lo pintoresco de nuestras ciudades... En nuestra naturaleza...Y también en nuestra historia." Alejo Carpentier (1904-1980)

¿Se puede considerar que América Latina está siguiendo los pasos de Europa en materia de secularización? No precisamente. Salvo el caso particular de Uruguay, con un $37 \%$ de su población considerándose no-religiosa, atea o agnóstica, en la amplia mayoría de los países sus poblaciones presentan un elevado índice de confesionalidad. Y ello se debe a que ambas regiones -Europa y América Latina- han seguido y siguen procesos socio-históricos, políticos y culturales distintos:

Las religiones en América Latina en la época del Papa Francisco son un libro abierto, contradiciendo una parte importante de lo establecido en el desarrollo de otras sociedades, como es el fenómeno de migración de religión en vez de secularización. (Latinobarómetro, 2014, p. 33).

Como se mencionó anteriormente, muchas de las predicciones que se habrían realizado a partir de los años sesenta del siglo XX 
sobre la progresiva y total secularización de Occidente han resultado equivocadas; la religión no sólo no ha desaparecido, sino que se está transformando, siendo una dimensión importante para comprender el desenlace de varios acontecimientos políticos y sociales, sobre todo en América Latina (Pérez, 2007; Blancarte, 2012). Ello lleva a pensar lo que es la secularización y cómo ésta en sí adquiere un sentido propio en el contexto latinoamericano, la cual está vinculada a la progresiva llegada de la Modernidad, cuyo arribo ha sido más una forma de aculturación en la región, no dándose igual en todos los estratos sociales, siendo asimilada sobre todo por las capas altas y educadas de las sociedades, ya que tal y como lo afirma Pérez (2007), la cultura latinoamericana en general sigue siendo profundamente religiosa, volcada a imaginarios providencialistas. Al ser tan extensa la literatura sobre la secularización, una discusión sobre esta estaría más allá de los alcances del presente artículo. Sin embargo, vale la pena indagar algunas nociones importantes desde nuestra realidad.

Hasta mediados del siglo XIX, la secularización básicamente significaba el paso de algo o alguien de la esfera religiosa a la civil, pero es también el paso de algo o alguien bajo control de una orden religiosa a la administración diocesana (Blancarte, 2008). En la actualidad, el término tiene significados plurales, como es la pluralidad uno de los distintivos de las sociedades a las que ha dado origen en los países donde más se ha asentado desde el siglo XVI: los del Atlántico Norte. Uno de los que mejor han planteado, a mi criterio, lo que es la secularización o la secularidad, es Taylor (2014), quien la entiende en tres sentidos: a. La desconexión existente en la mayoría de los Estados occidentales modernos entre la organización política de la sociedad y la fe en Dios. O por lo menos, algún sentido de Realidad Última que lo sustenta y lo integra todo. Esto crea una profunda diferencia respecto a las sociedades premodernas, y es lo que se conoce genéricamente como la separación Estado-Iglesia.

b. La ausencia-erradicación de la fe en Dios y lo religioso de los espacios públicos. La religión pasa a ser un asunto privado, algo ya afirmado a finales de la década de los 60 por Luckmann (1967). Lo anterior va aparejado con la consecuente fragmentación de la vida social en varias esferas, no necesariamente relacionadas entre sí: política, económica, social, educativa, moral, recreativa, entre otras. La religión ya no tendría incidencia sobre todas como sí ocurría en las sociedades premodernas.

c. La fe en Dios pasa de ser la opción de vida, a una opción entre muchas otras. Es decir, la dimensión cualitativa de la experiencia religiosa, de la fe, ya no es tanto un asunto trascendental, una opción fundamental que comprometa, sino una opción más perteneciente a un amplio abanico de opciones y estilos de vida en las sociedades pluralistas. Y es una opción que, como el mismo Taylor admite, no es la más fácil de asumir. La fe en Dios pasa a ser una cuestión de gusto, elegible, dispensable.

Ciertamente, los tres sentidos aparecen en la mayoría de sociedades occidentales-incluida América Latina- y en el caso del tercero, el punto medular está en que lo religioso va perdiendo ese carácter de religación, 
orientado hacia una Realidad trascendente que interpela a todas las esferas de la vida individual y social, para ser sólo una opción privada, entre muchas otras. Esta es la tendencia actual que se puede observar no sólo en ese sector latinoamericano que rechaza la vinculación a una religión, sino incluso entre quienes se identifican como católicos o protestantes: existe una tendencia a vincularse a la religión de una forma selectiva, individualizada.

Otras formas de comprender la secularización son también la de un proceso en el cual "algunos sectores de la sociedad y de la cultura son sustraídos de la dominación de las instituciones y los símbolos religiosos" (Berger, 1981, p. 154; citado por Blancarte, 2012, p. 63). Berger ciertamente fue muy acertado al afirmar que son "algunos sectores", pues probablemente tenía noción de que dicha tendencia intelectual y política no es mayoritaria, como fácilmente lo demuestra la realidad social en el caso latinoamericano.

La secularización, más que erradicar a Dios de la sociedad como sostienen erróneamente grupos religiosos fundamentalistas en el ámbito político de nuestra región, ha venido a pluralizar, a complejizar la organización política y social, dando como resultado que sólo en algunos sectores la increencia sea predominante, pero la indiferencia hacia lo religioso, hacia la religión institucionalizada, sí sea una tendencia cada vez más preponderante. La secularización es, así, un proceso de diferenciación social, de separación de ámbitos (político, social, cultural) que diverge sustancialmente de la organización existente en las sociedades medievales. Dicho proceso ha tenido como fin sustraer el orden temporal a la influencia religiosa, al menos de manera formal, pues se aprecia cómo en el mismo lenguaje y en los imaginarios sociales a los que éste puede dar lugar, sigue perviviendo una dimensión profundamente religiosa.

En este sentido, la secularización en América Latina adquiere unas características distintas, vinculadas al contexto histórico de los países latinos (España, Portugal, Francia, Italia, entre otros), donde algunos autores, como Blancarte (2008), consideran que a diferencia de los países anglosajones, en América Latina se hablaría más bien de "laicidad" (origen mayormente francés), o lo "laico", en contraposición a lo religioso, clerical. Cabe tomar en cuenta que los términos "secularización", "laicidad" o "laico" tienen un origen religioso en el seno del Catolicismo, cuyo significado, como se vio, venía a referirse a la distinción entre el pueblo cristiano y el clero, a las realidades temporal/divina, inmanente/trascendente, distinción cuyo establecimiento concreto ha ido variando progresiva y a veces agresivamente, desde la segunda mitad del siglo XIX a la actualidad, pero cuyas raíces ya pueden rastrearse hasta la Reforma protestante del siglo XVI. Laicité y sécularisation vendrían a tener prácticamente el mismo fin; sin embargo, Taylor se referiría más al segundo. Así, Blancarte afirma:

Lo laico, en los países latinos, y lo secular en los países anglosajones, hacía referencia, a partir de ese momento (a mediados del siglo XIX), a la creación de un espacio temporal independiente de la influencia religiosa. 
La idea de preservar la libertad de conciencia había conducido a una "privatización" de lo religioso y a su consecuente marginación de la esfera pública. Esta autonomía de acción del poder temporal respondía al ideal liberal y a las necesidades sociales, por ejemplo en materia de desarrollo científico. (p. 142)

En términos sustanciales, históricamente sigue manteniéndose un origen religioso, sobre todo católico, en la conformación actual de las sociedades occidentales, en sus diferentes contextos, enterrado y a veces desenterrado cuando los líquidos referentes axiológicos no dan un sentido a la existencia. En América Latina, la lucha por la creación de dicho espacio temporal independiente de lo religioso, como la formulación de políticas en tal línea, ha implicado muchas veces el enfrentamiento con la Iglesia Católica, al ser esta la comunidad y la institución religiosa predominante en las sociedades latinoamericanas, la cual inclusive logró mantener una hegemonía importante tras las luchas y las victorias independentistas a inicios del siglo XIX, participando íntima y activamente en la construcción de los estados en la mayoría de países. En este sentido, la implantación de un modelo estatal propio del contexto europeo -en consonancia con las ideas liberales- a una realidad sociocultural latinoamericana que es distinta, caracterizada por una marcada religiosidad, por desigualdades sociales, económicas y étnicas no superadas, ha generado una divergencia que se mantiene hasta hoy en día.

Pérez (2007), siguiendo al escritor mexicano Carlos Fuentes, lo expone de manera sucinta, remitiendo la cuestión al mismo Estado: "El trasplante de la idea del Estado moderno europeo a América Latina fue el comienzo de lo que Carlos Fuentes ha caracterizado como la tensión, aún no resuelta, entre el «país legal» y el «país real»." (p. 79). En este sentido para dicho autor, mientras que las élites latinoamericanas impulsaban la construcción de los estados amparados por el liberalismo político, la cultura política y religiosa en América Latina era y sigue siendo "premoderna", pero no en un sentido peyorativo, ni partiendo de una concepción lineal de la historia, sino en cuanto a sus coincidencias con el pensamiento medieval europeo, donde Dios es quien en última instancia sostiene y da sentido a la historia, diferenciándose de la concepción moderna, donde es el ser humano el que construye su propia historia:

Ya desde el Renacimiento, pero sobre todo a partir de la gran crisis del siglo XVI - generada por la revolución de Copérnico, la Reforma, el surgimiento del capitalismo y otros procesos-, la humanidad se elevó, en la visión de los europeos, a la condición de copartícipe de la creación del mundo y su historia. (Pérez, 2007, p. 79)

La secularización como proceso político y cultural se sustenta en esta nueva concepción, la cual alcanzó su maduración en los ambientes burgueses europeos hacia el siglo XVIII (Duch, 2012). Se puede afirmar, entonces, que la secularización en América Latina sí se da como proceso, es identificable, pero no es absoluta ni uniforme, sino que se configura de forma distinta, bajo una compleja tonalidad cultural 
que paradójica e históricamente ha bebido de unas fuentes católicas. Desde la institucionalidad política hasta la cultura religiosa como hasta la dinámica política, la conciencia nacional surgió en los nacientes estados latinoamericanos a la par de la presencia de la Iglesia Católica como institución aglutinadora de los distintos sectores sociales (Núñez y Núñez, 2012). Prueba de ello fue y ha sido la connivencia que el Estado y la Iglesia Católica mantuvieron en numerosos momentos tras alcanzada la independencia en la mayoría de los estados latinoamericanos. La triple alianza que menciona Levine (2006) entre el Estado, la Iglesia Católica y el Ejército, tuvo su mayor auge durante el siglo $\mathrm{XX}$, para abrirse ahora a una pluralidad religiosa que se mantiene en constante evolución.

En definitiva, la región latinoamericana no se caracteriza por una marcada descristianización como en el caso de Europa, o bien por el "desencantamiento" del mundo -que algunos como Taylor mencionan- sobre los procesos de transformación social, política y religiosa a los que la secularización dio origen. Ello no ocurre en estos lares, donde lo religioso tiene una profunda influencia en todos los ámbitos de la vida subjetiva y social: en la vivencia y significación de las experiencias personales, en la construcción de los valores, en la afiliación política, en el lenguaje, el folclor, el arte, la estética, en fin, en los imaginarios socioculturales y en la constitución de las identidades, al punto de que no se puede entender nuestra región sin lo religioso.

Quien quiera elaborar un análisis integral de la realidad histórica y sociocultural latinoamericana sin ahondar o siquiera tomar en cuenta la dimensión religiosa, presentará una visión sesgada e incompleta, y es ahí donde se puede cuestionar a cuáles intereses ideológicos responde. En este sentido, se comparte la crítica de Iranzo y Manrique (2015), en cuanto a que existe una insuficiencia conceptual y analítica para dilucidar, por ejemplo, cómo se da la relación entre religión y política en nuestra región. Es necesario considerar que si bien el concepto mismo de la secularización origina y sustenta las tendencias actuales hacia lo religioso en la región, es también muchas veces una salida fácil para evitar indagar en nuestra compleja historia religiosa, en la compleja y problemática relación, por ejemplo, que se da entre religión y política. Dicho esquema de la secularización se basa en principios políticos liberales que se han convertido en normativos, en determinantes para la estructuración de los Estados latinoamericanos y de las élites intelectuales y políticas que los promueven, o los imponen, pero que no necesariamente tienen eco en el entramado social, en la psicología popular, profundamente religiosa como diversa en sus identidades.

Las ideas secularizadoras, tanto las que se adhieren a un virulento laicismo de grupos radicales que han pregonado la erradicación total de la religión de los espacios públicos y políticos, como las que se enmarcan en una más conciliadora laicidad, son en última instancia una importación cultural de Norteamérica y Europa que data desde los albores de la independencia de los estados latinoamericanos en el siglo XIX, y que se agudizó en el enfrentamiento a mediados de ese siglo entre las élites liberales y la Iglesia Católica cuando se 
emprendió la constitución de los estados; conflicto que adquirió distintos rumbos en cada país, conforme iba construyéndose su identidad nacional.

La secularización fue, así, uno de los pilares que sustentó la conformación de las presentes sociedades, el cual fue promovido por las élites liberales criollas que en su momento se sublevaron ante la Monarquía española (Núñez y Nuñez, 2012), e impulsado por algunos de los grandes próceres de la independencia, como por otros políticos e intelectuales hasta el presente. Sin embargo, en dicho enfrentamiento claramente existía una disputa de poder, una lucha del Estado por apropiarse de la influencia social que la Iglesia Católica ha poseído, como también por controlarla y disponer de ella según los vaivenes políticos. Como lo menciona Lynch (2012): "El Estado quería las mismas facultades que la Corona española había poseído sobre la Iglesia: controlar los nombramientos más importantes, recuperar recursos, ser la única autoridad sobre la política nacional y que Roma se mantuviera al margen." (p. 252) Este enfrentamiento no necesariamente fue emulado por el pueblo de a pie, el cual era y sigue siendo en su mayoría muy religioso como lo podemos ver en los estudios mencionados.

No habría diferencia entre argumentar que el Cristianismo es una herencia de los europeos, si las mismas corrientes intelectuales y políticas que cuestionan esto caen en la contradicción de querer limitar, erradicar o controlar su presencia sociopolítica bebiendo de las aguas ideológicas de dicho continente, algo que se ve potenciado por la lógica de mercado y por la interconexión entre distintas regiones que suscita la globalización (Steger, 2009). En línea con el pensamiento de algunos pensadores y ensayistas latinoamericanos como Carlos Fuentes o Leopoldo Zea, la identidad cultural latinoamericana oscila en una serie de contradicciones históricas internas, en un gestarse a partir de estas; sugiere una complejidad que merece ser analizada con cuidado en otros espacios.

En la actualidad, todo este proceso ha dado como resultado una situación particular, en la cual el Cristianismo -tanto la Iglesia Católica como las Iglesias protestantes- a diferencia del contexto norteamericano-europeo, no ha experimentado una crisis tan aguda y demoledora como religión organizada, con una tradición consolidada durante siglos y con una importante presencia en todos los ámbitos de las sociedades. Como lo afirmaría Taylor (2014) desde el contexto anglosajón: "La fe en Dios ya no es axiomática" (p. 23), pero ello no necesariamente aplica en el contexto latinoamericano, si bien hay indicios que sugieren que ciertos sectores podrían estar en camino a ello.

Por el momento, sin embargo, no se puede hablar aquí de descristianización o de una marcada secularización, entendida en el tercer aspecto enumerado por Taylor. Lo religioso más bien se encuentra en una especie de mutación, de hibridación, de transformación en su composición, en la distribución confesional. Si bien la Iglesia Católica sigue siendo la comunidad religiosa más grande e influyente, en las últimas décadas del siglo XX hasta la actualidad, ha tenido que aprender a compartir y negociar el espacio sociopolítico 
con una variedad de Iglesias protestantes, las cuales presentan un auténtico desafío a la organización política, pues su acelerado e impredecible crecimiento ha llegado al punto de penetrar en las instituciones políticas, legislativas, lo cual, por ejemplo, es muy patente en Costa Rica con la reciente elección de un pastor evangélico como presidente de la Asamblea Legislativa. Es una situación que para muchos genera roces en la delimitación constitucional entre Estado e Iglesia, la cual está prácticamente ausente en la constitución costarricense, históricamente confesional, pero que hoy en día choca incluso con la postura adoptada por papas como Juan Pablo II, Benedicto XVI y Francisco I, partidarios de una separación cordial entre Estado e Iglesia.

El contexto latinoamericano es, así, distinto; su secularización lo es; en nuestra región lo religioso, independientemente de cómo se juzgue, continúa teniendo un peso indiscutible en todas las dimensiones de la vida política, social, cultural, artística, ética, en definitiva, en lo cotidiano, subjetivo. Por lo tanto, el ser latinoamericano, con la enorme riqueza cultural que le caracteriza, pero también con su fragmentación, sus contradicciones, está históricamente atravesado de pecho a espalda por la religiosidad, principalmente cristiano-católica. Discutir estos aspectos es necesario para la construcción de una convivencia social pacífica y consensuada, donde no se caiga en la ingenuidad que niega los conflictos, sino de saber integrarlos en el panorama.

\section{El dilema soterrado: los "católicos culturales"}

\author{
"Quien no vive como piensa, \\ termina pensando como vive." \\ San Agustín de Hipona (354-430 d.C.)
}

En el sondeo sobre la situación religiosa en América Latina, y aparejado al fenómeno de la secularización sobre el cual ya se ha discutido, aparece otro fenómeno vinculado a esta, pero que no es tan evidente, más bien sutil, verbalmente escondido en el entramado sociocultural; es el de los "católicos culturales". Es importante esbozar una definición que permita entrever a qué nos referimos con este término: en un nivel general, son personas que han nacido y crecido en un entorno cultural y religiosamente católico, muy probablemente han sido bautizados en dicha fe, como lo indica el representativo $84 \%$ de la población latinoamericana que ha pasado por dicho sacramento, mencionado por el Pew Research (2014). Sin embargo, y por distintos motivos, muchas personas, posteriormente, no se identifican con el Catolicismo, o lo hacen de manera parcial; otras se desmarcan, distancian e incluso algunos(as) han llegado a mantener una postura altamente crítica o de rechazo hacia todo lo que representa la Iglesia Católica. Aun así, la realidad histórica y cultural en la cual se mueven, la lengua materna, significación de experiencias, educación, estructura de valores, o al menos principios éticos orientadores de los que se dispone; en fin, el ser y estar en el mundo se hallan culturalmente permeados por los contenidos de la fe católica. Por lo cual ese otro $16 \%$ que no ha sido bautizado se halla igualmente inmerso en una cultura 
de tradición católica. No se pretende poner en tela de juicio la libertad del sujeto para elegir o construir su identidad, valores y significados, ello es en sí un proceso muy subjetivo que se asume de una forma particular, y es siempre una posibilidad abierta. La intención es hacer evidente lo que muchas veces no lo es : el sustrato arquetípico, simbólico y conceptual desde el cual se han construido los sujetos y las sociedades desde América Latina tiene un origen cultural e histórico que bebe no exclusivamente, pero sí principalmente, de la cosmovisión católica.

La vida social, para muchos, se debate en el hecho de estar en una cultura de matriz religiosa cristiano-católica que los constituye e interpela; es identificarse como parte de dicha religión de manera total o parcial, o no profesarla e incluso rechazarla, manteniendo una postura crítica. Ser católicos culturales sin asentir dicha fe, sin vivir por elección según sus contenidos, es una de las tantas situaciones bizarras, propias de las sociedades contemporáneas, y de las más interesantes teológicamente hablando. Es una constante transición entre mundos, entre realidades históricas disímiles, que puede dar lugar a situaciones paradójicas, carentes de sentido para muchos, indiferente para otros. Es un dilema para quien se lo plantea como tal, pues para más de una persona perfectamente puede ser una cuestión sin importancia, que no genere mayor escozor mental. No obstante, para quien crea que es irrelevante, se le invita a pensarlo dos veces, pues debates éticos y políticos actuales como por ejemplo: la despenalización del aborto, la eutanasia, la fertilización in vitro, la legalización de la unión entre personas del mismo sexo, la relación entre política y religión, el pluralismo religioso y cultural, la libertad de consciencia y demás, parten siempre de unos valores y fines últimos, de una determinada concepción de sujeto en una u otra postura; de una serie de principios éticos y filosóficos que sustenten los debates mismos, como los marcos legales que se hallan en la constitución política de las naciones, y en el caso de América Latina, dicho sustrato ha sido históricamente católico, el cual tampoco ha sido ajeno a las tradiciones culturales locales con las cuales ha entrado en contacto.

Ahora bien, decir que los latinoamericanos son "católicos culturales", independientemente de si se practica dicha fe o no, remite a la discusión sobre cómo entendemos lo religioso: si como una experiencia y un estilo de vida que parten de un fin último, fundamental para el sujeto, que asume libre y conscientemente vivir conforme a su doctrina y su ética, o como sistemas de creencias e instituciones cuya influencia histórica y cultural perdura en las sociedades, independientemente de la elección de cada persona de profesarla o no. La respuesta discurre en ambas formas. Es tan cierto que la religión es un complejo sistema simbólico de creencias, una experiencia de fe que es asumida de forma libre y consciente, como también es cierto que en sus distintos contextos geográficos son instituciones que moldean: la cultura, el arte, la moral, el derecho, en general, la vida social y subjetiva. A decir de Velasco (2002):

...las religiones han acompañado todas las etapas de la historia humana; han modelado la vida y la 
cultura de los pueblos; han dejado su huella en las lenguas de la humanidad; se han manifestado en las grandes creaciones artísticas; se han mezclado con los avatares de la política. (p. 1)

Católicos culturales, por otra parte, pueden ser aquellas personas que se identifican a sí mismas como católicas, pero que no aceptan todos los contenidos de la doctrina de la Iglesia, asisten de vez en cuando a las actividades religiosas (misas, procesiones, etc.), más por un sentido de tradición o de vinculación familiar que por una profunda convicción que les mueve y les trasciende, y tienen sus propias perspectivas en torno a la doctrina católica; posiblemente en contra de lo definido por la Tradición y el Magisterio eclesiástico, sin sentirse, por ello, fuera de dicha comunidad. Es la primacía del individuo sobre lo comunitario e histórico que le precede, y es algo que se observa sobre todo en las generaciones más jóvenes (Rodríguez, 3 de abril de 2015). De ahí que el $69 \%$ o $67 \%$ de quienes se identifican como católicos -según los estudios del Pew Research y del Latinobarómetro respectivamente- no sean cifras uniformes, ni absolutas, sino altamente relativas, pues en buena parte éstas se basan en el número de personas que han sido bautizadas. Por ende, ¿cuántas personas de ese 69\%-67\% se identifican a sí mismas como católicas involucradas activamente con su fe, en la vida de la Iglesia? ¿Cuántas conocen el significado teológico, religioso y experiencial del sacramento del Bautismo y de los demás sacramentos? ¿En qué medida varía el nivel de aceptación de las doctrinas y la vinculación con las comunidades?
Y así podría continuarse. Este fenómeno nos remite a las relaciones entre sujeto $\mathrm{y}$ cultura, entre la interioridad de la persona y su relación con una sociedad y una historia que le preceden.

Un punto interesante que nos aporta una disciplina como la Psicología cultural es que si se sigue lo afirmado por Bruner (2015) y Guitart (2009) sobre la cultura como una compleja red de significados que son negociados y consensuados por los sujetos, la mente y la cultura se constituyen mutuamente. Se entendería por qué es importante analizar, discutir y comprender el sustrato cultural, histórico, religioso y simbólico de América Latina, y cómo éste sigue perviviendo en nuestro ser latinoamericano(a) secularización $y$ globalización incluidas. A su vez, la tendencia hacia el pluralismo y la diversidad que también se vislumbra en ambos estudios se puede visualizar como aquella interacción entre sujeto y cultura en la que el primero no es un mero agente pasivo de la segunda, sino que también la redefine desde su experiencia de ser y estar en el mundo. Por eso es que no se cuestiona la libertad y posibilidades de las personas para redefinirse ante una determinada herencia histórica y cultural, ya que las personas transforman su cultura, a la vez que ésta las transforma a ellas. Es una interacción dinámica, conflictiva y constitutiva.

El Cristianismo católico en América Latina ha sido y es una religión institucionalizada, oficial de los estados en varios momentos históricos, pero es también una activa comunidad de fe, que participa en la sociedad y contribuye con numerosas causas sociales. Las raíces culturales 
latinoamericanas también han surgido a partir de su profunda influencia en las sociedades, donde sigue presente junto a la creciente diversificación religiosa de la región. Lo anterior posee mucha relación con el tercer aspecto de la secularización que menciona Taylor (2014): el de las transformaciones en la dimensión cualitativa de lo religioso, de la fe. Si bien la aceptación y vivencia de la fe católica -sobre todo a partir del Concilio Vaticano IIse entiende como una acción consciente que debe partir de un espacio de reflexión y libertad, es también palpable el universo cultural que el Catolicismo ha contribuido a cimentar en América Latina y en el cual se mueven los sujetos. Legorreta (2013) lo enfatiza de manera precisa:

Hay un núcleo de valor y pautas en la vida de los pueblos latinoamericanos, donde la evangelización ha sido tan profunda, que es constituyente de su ser. Este núcleo cultural básico forma los pilares de la vida cotidiana de nuestros pueblos. Atraviesa variadas formas y grupos sociales, y aún quienes lo distorsionan o niegan están referidos a esa universalidad de modo explícito o implícito. Es una estructura vida, no tematizada necesariamente como tal. (p. 79)

Así, el fenómeno de los "católicos culturales" no sólo incide en las sociedades latinoamericanas, sino también en las mismas comunidades católicas, en su experiencia de fe, en su autocomprensión social, teológica y política, puesto que en última instancia son las más afectadas, y no de manera exactamente positiva, ya que lo anterior posee consecuencias importantes para la Iglesia Católica. Es lo que Campuzano -desde los países anglosajonesdenomina como "catolicismo cultural": "El catolicismo desafortunadamente se convirtió en una experiencia cultural más que una experiencia de aceptación de esa fe y la implicación de esa fe en la vida" (Rodríguez, 2015). En el nivel teológico, es importante considerar que el Cristianismo, en última instancia, no necesita identificarse con ninguna cultura en particular para dar a conocer lo que constituye su esencia, su fundamento como experiencia humana del Dios amoroso, inefable y absolutamente Otro que han testimoniado, por ejemplo, tantos místicos cristianos, hombres y mujeres de distintas épocas y procedencias culturales. Si bien el Cristianismo posee un origen histórico, cultural y social que puede ser localizado, no es una realidad monolítica, anclada a una cultura en particular, sino que es una comunidad donde la experiencia de fe está viva y en constante evolución a partir de su filiación a la persona de Jesucristo, a la Realidad trascendente a la cual responde.

No obstante, lo afirmado por Campuzano es muy acertado en cuanto que el catolicismo cultural es reflejo de la crisis que ha tenido que afrontar dicha institución y comunidad de fe en las últimas décadas que, como se afirmó, no es tan crónica como en Europa y Norteamérica, pero si se refleja en el descenso del número de católicos hasta el $69 \%$ indicado por el estudio del Pew Research (2014), o 67\% del Latinobarómetro (2014). Se ha venido generando en la Iglesia Católica una tendencia que es propia de las sociedades posmodernas y secularizadas: la privatización-individualización de lo religioso, lo 
que puede causar la fragmentación de las comunidades parroquiales y el crecimiento de una indiferencia o selectividad hacia el compromiso existencial que supone asumir dicha fe de manera integral, como también una relativización de la doctrina católica que en última instancia puede ser muy poco informada. Se ha ido desnaturalizando la idea de que lo religioso efectivamente conlleva un compromiso total de la persona con un Dios que le constituye y trasciende en el amor, un Dios que es la más íntima de todas las aspiraciones, pasando a ser sólo un bien de consumo, algo dispensable cuando no agrade, adaptable a las cambiantes necesidades y vaivenes de la condición humana.

Claramente, esta situación varía de país en país, pero todo lo anterior va muy en consonancia con la tendencia posmoderna en las sociedades occidentales hacia la desestructuración en todos los ámbitos e instituciones fundantes. Una tendencia identificada y discutida ya desde mediados de la década de los 90 por varios autores como Mardones (1996), quien analiza este fenómeno desde la situación en que se encuentra la Iglesia Católica en España. Es algo que atraviesa a las sociedades como un todo, y no sólo el Catolicismo empieza a experimentar los síntomas de una crisis de legitimidad, sino todas las instituciones fundantes de la civilización occidental. En el contexto católico, ello ha significado no sólo el conocido y creciente abandono de sus filas, sino también una des-institucionalización en sus fieles, una ligereza en la interpretación dogmática, un reblandecimiento institucional que muestra un mayor acento en el individuo y no tanto en la institución, o la comunidad. Son muchas las causas que se han propuesto para esta crisis, desde quienes la adjudican a la Iglesia misma, mostrando más la virulencia e irracionalidad de su rechazo a dicha institución que un verdadero análisis constructivo, o están aquellos que emigran al otro extremo, culpando a la sociedad occidental misma, atrincherándose en un violento y ciego fundamentalismo que rechaza todo lo que ésta representa.

Con independencia de uno $\mathrm{u}$ otro caso, no hay duda de que somos testigos de una progresiva diversificación que se está dando en todas las sociedades del mundo occidental, incluida Latinoamérica. Una diversificación en lo político, religioso, educativo, cultural e identitario que ha traído grandes beneficios a las sociedades como un todo, tales como una mayor riqueza de experiencias interculturales, una consciencia más profunda de la alteridad del otro, la visibilización de la polifonía que conforma los espacios sociales, la reivindicación de los derechos de grupos históricamente marginados como los pobres, los niños(as), las mujeres y los pueblos indígenas o afrodescendientes, entre muchos otros.

Vale destacar también -desde una postura más cauta- la falta de criticidad de cómo este pluralismo puede ser también un subproducto de la lógica de mercado que rige actualmente en el mundo globalizado, en el que utópicamente se aspira a que el mercado sea el único referente existencial de la vida social y subjetiva. Paradójicamente, se celebra el pluralismo en todas sus formas, so pena de caer en la superficialidad misma, pero en última instancia dicho pluralismo es definido monopolísticamente por una lógica de consumo. El punto no es condenar el pluralismo 
como tal, éste es parte de la condición humana y alude a nuestro potencial creativo como especie, y desde la visión católica, como imagen del Dios creador; el punto es problematizarlo, des-idealizarlo, pues resulta cada vez más difícil de aceptar la manera en que es asumido acríticamente en las sociedades occidentales, capitalistas, basadas en una economía de mercado. Sorprende, incluso por momentos, la miopía respecto al hecho de que esta realidad históricamente predominante y en desarrollo desde el siglo XVI es la que preestablece los esquemas mentales desde los cuales, irónicamente, se pretende resistirla. Es un círculo vicioso.

Desde el Catolicismo, se podría pensar que las reformas propuestas por el Concilio Vaticano II allá por la década de los 60 cuando se empezaron a observar todas las tendencias comentadas, buscó renovar y reavivar el compromiso eclesial, como también la vivencia interior de la fe. Han surgido dudas sobre si esta renovación ha surtido el efecto deseado, sobre todo en materia litúrgica, la cual fue justamente la primera y una de las mayores reformas realizadas en la Constitución Sacrosantum Concilium. Esto si se considera que los dos principales motivos por los cuales los latinoamericanos se han unido a otras Iglesias cristianas son los de buscar una conexión más personal con Dios y un mayor disfrute del estilo de culto en dichas iglesias (Pew Research Center, 2014). Sin embargo, es apresurado afirmar que dichas reformas no fueran efectivas, pues se debe considerar una amplia variedad de factores, como también la realización de más investigación al respecto; es una cuestión abierta. Sí es cierto y evidente que la actual situación en materia religiosa denota, a su vez, las progresivas transformaciones sociales, éticas y políticas de las que América Latina es partícipe a partir de la globalización de un mundo que en sí resulta prometedor para unos cuantos, cada vez más ajeno para muchos, diverso y polisémico para otros, y conflictivo para una buena parte de la humanidad.

Siguiendo lo estipulado por el Vaticano II en torno a la libertad religiosa -sobre todo en la Declaración Dignitatis Humanae- en nuestra época, por otra parte, se ha abierto la posibilidad de que la experiencia religiosa que nace de la fe no sea ya un mero fruto de las raíces culturales, de un adoctrinamiento iluso ni de la coerción externa, sino la manifestación viva de una decisión íntima y coherente, socialmente comprometida. El gran teólogo católico Karl Rahner (1982) lo expresó de una forma inigualable:

Hoy es más necesaria que nunca la decisión personal. De ahí que pertenezca a la espiritualidad actual del cristiano el valor para la decisión personal en solitario, en contra de la opinión pública. En esto se parece al valor de los primeros siglos del cristianismo, la época de los mártires. Y tanto más cuanto que hoy la misma expresión eclesial y pública de la fe no se dedica a apoyar la decisión del individuo sino que más bien depende de ésta. Ahora bien, tal valor personal sólo es posible a partir de una profunda experiencia individual de Dios y de su Espíritu. (p. 1)

De acuerdo con los signos de los tiempos, dicha crisis puede más bien fomentar el resurgimiento de aquella renovación 
institucional y comunitaria en la Iglesia que fue proyectada por Vaticano II. Es deseable la generación de un entorno social, comunitario, que sea potencialmente fecundo para que la fe no sea ya una imposición externa que traiciona su esencia, sino que más bien sea una profunda experiencia de Dios, de un talante místico y liberador, socialmente consciente, trascendente, donde se realza la condición humana, en el mejor sentido del Evangelio y de lo planteado por los Padres de la Iglesia. Donde se recupere la esencia de lo afirmado por San Ireneo de Lyon allá por el siglo II d.C.: "Gloria dei homo vivens": La gloria de Dios es la vida del ser humano.

\section{Bibiografía}

Berger, P. (1981). Para una teoría sociológica de la religión. Segunda edición. Barcelona: Editorial Kairós. Citado en Blancarte, R. (2012). Religión y sociología; cuatro décadas alrededor del concepto de secularización. Estudios sociológicos 30, 59-81. Recuperado de: http://www. jstor.org/stable/43202516

Blancarte, R. (2008). Laicidad y laicismo en América Latina. Estudios sociológicos 26(76), 139-164. Recuperado de: http://www.jstor.org/ stable/40421162

Blancarte, R. (2012). Religión y sociología; cuatro décadas alrededor del concepto de secularización. Estudios sociológicos 30, 59-81. Recuperado de: http://www.jstor.org/ stable/43202516

Bruner, J. (2015). Actos de significado: Más allá de la Revolución Cognitiva. Madrid: Alianza Editorial.
Cipriani, R. (2015). Religión difusa en América Latina. Sociedad y religión 44(25), 269-278. Recuperado de: http://www.scielo.org.ar/ scielo.php?script=sci_arttext\&pid $=$ S1853-70812015000200012

Corporación Latinobarómetro (2014). Las religiones en tiempos del Papa Francisco. Santiago de Chile. Recuperado de: http://www.latinobarometro.org/latNewsShowMore. jsp?evYEAR=2014\&evMONTH=-1

De la Torre, R., Gutiérrez, C., Juárez, N. (2009). New Age in Latin America: Popular variations and Ethnic Appropiations. Londres: Brill.

Duch, L. (2012). La religión en el siglo XXI. Madrid: Siruela.

Ferrer, A. (2013). Historia de la Globalización I: Orígenes del orden económico mundial. Segunda edición. México D.F.: Fondo de Cultura Económica.

Ferrer, A. (2013). Historia de la Globalización II: La Revolución Industrial y el segundo orden económico mundial. Segunda edición. México D.F.: Fondo de Cultura Económica.

Guitart, M. (2010). Geografías del desarrollo humano: Una aproximación a la Psicología cultural. España: Aresta.

Iranzo, A., Manrique, C. (2015). Religiones, post-secularidad y democracia en América Latina: reconfiguraciones del discurso y la acción política. Revista de Estudios Sociales 51, 9-22. Recuperado de: http://www.redalyc.org/ $\mathrm{html} / 815 / 81535389001 /$

Levine, D. (2006). Religión y política en América Latina: La nueva cara pública de la religión. Sociedad y 
Religión: Sociología, Antropología e Historia de la Religión en el Cono Sur 18(26-27), 7-29. Recuperado de: http://www.redalyc.org/ pdf/3872/387239033002.pdf

Legorreta, J. (2013). Modernidad, secularización e Iglesia en América Latina. Los obispos latinoamericanos y el cambio cultural. México D.F.: Universidad Iberoamericana.

Luckmann, T. (1967). The Invisible Religion: The Problem of Religion in Modern Society. Londres: McMillan Publishing Company.

Lynch, J. (2012). Dios en el Nuevo Mundo: Una historia religiosa de América Latina. Barcelona: Crítica

Mardones, J.M. (1996). ¿Hacia dónde va la religión? Cristianismo y religiosidad en nuestro tiempo. Santander: Sal Terrae

Núñez, C., Núñez, M. (2012). La Religión y el Estado Hispanoamericano. Madrid: Dikinson S.L.

Pérez, A. (2007). Dios y el Estado: Dimensiones culturales del desarrollo político e institucional de América Latina. Nueva Sociedad 210, 78-94. Recuperado de: http://nuso.org/articulo/dimensiones-culturales-deldesarrollo-politico-e-institucionalde-america-latina $/$ ?page $=2$

Pew Research Center (2014). Religión en América Latina: Cambio generalizado en una región históricamente católica. Recuperado de: http:// www.pewforum.org/files/2014/11/ PEW-RESEARCH-CENTER-Religion-in-Latin-America-Overview-
SPANISH-TRANSLATION-forpublication-11-13.pdf

Rahner, K. (1961). Escritos de Teología III: Vida espiritual-sacramentos. Madrid: Taurus Ediciones.

Rahner, K. (1982). Ser cristiano en la Iglesia del futuro. Selecciones de Teología 84(21), 65-67. Recuperado de: http://www.seleccionesdeteologia. net/selecciones/llib/vol21/84/084_ rahner.pdf

Rodríguez, L. (3 de abril de 2015). El Catolicismo cultural: "Una "tradición, no una experiencia religiosa". Chicago Tribune. Recuperado de: http:// www.chicagotribune.com/hoy/cthoy-8439319-el-catolicismo-cultural-una-tradicion-no-una-experiencia-religiosa-story.html

Steger, M. (2009). Globalization: A very short introduction. New York: Oxford University Press.

Taylor, C. (2014). La era secular. Tomo I. Barcelona: Editorial Gedisa.

Tizzano, P. (2012). La traducción religiosa y su impronta filosófica en el nivel de la praxis: El budismo en América latina. Mutatis Mutandis 5(1), 17-39. Recuperado de: https:// dialnet.unirioja.es/descarga/articulo/5012609.pdf

Velasco, J.M. (2002). El hombre y la religión. Madrid: PPC Editorial y Distribuidora.

Zea, L. (1976). El pensamiento latinoamericano. Tercera edición. Barcelona: Editorial Ariel. 

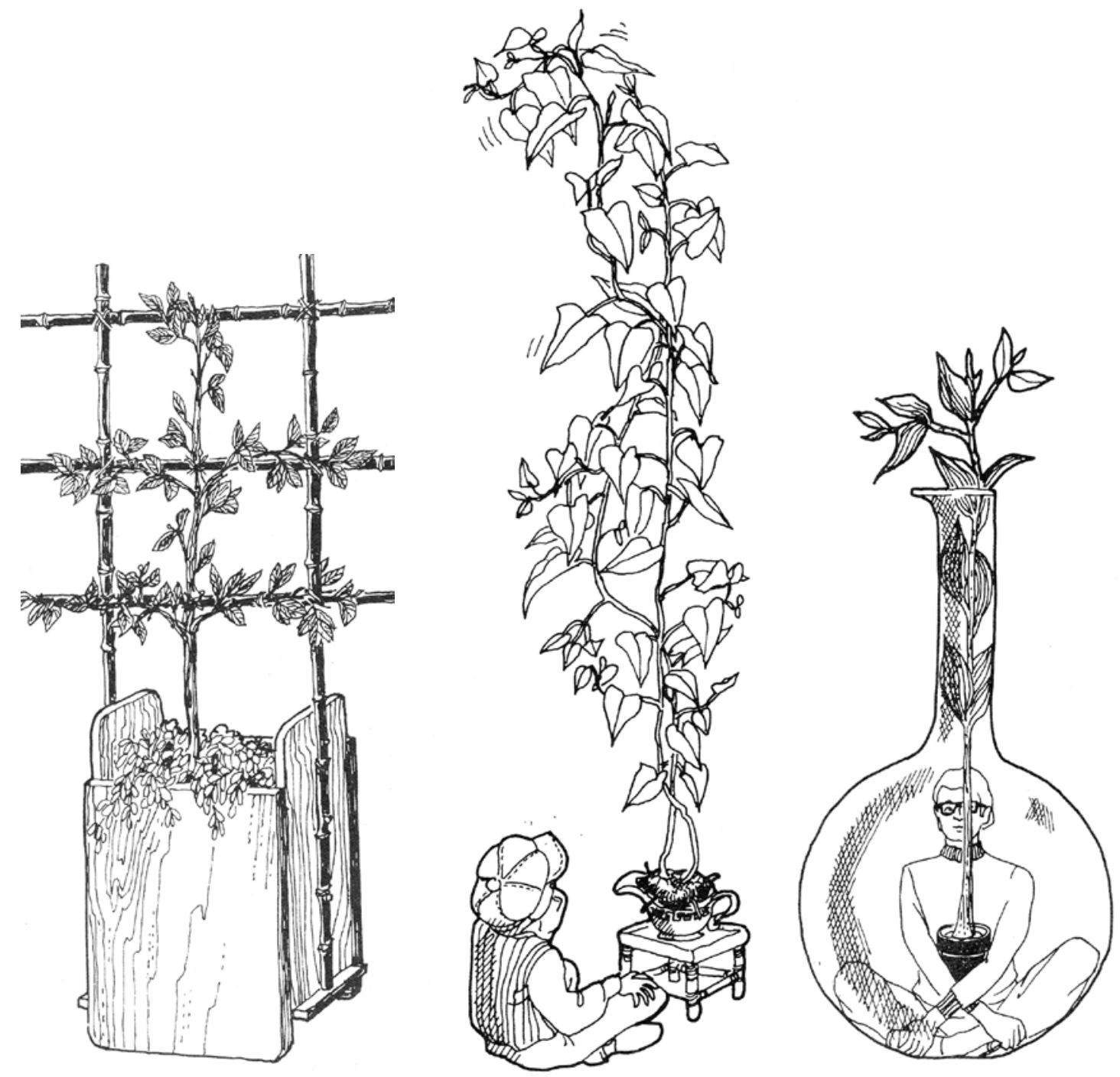

Sergio Rojas Chaves

Intelectuales y medio ambiente Dibujo digital 2017 